J Venom Anim Toxins incl Trop Dis, 2019 25: e148818

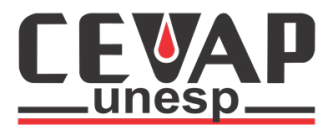

\author{
The Journal of Venomous Animals and \\ Toxins including Tropical Diseases \\ ISSN 1678-9199 \\ Journal homepage www.jvat.org
}

\title{
Neuroprotective properties of RT10, a fraction isolated from Parawixia bistriata spider venom, against excitotoxicity injury in neuron-glia cultures
}

\author{
Eduardo Octaviano Primini ${ }^{1}$ (D), José Luiz Liberato ${ }^{1,2}$ (1), Andreia Cristina Karklin Fontana ${ }^{3}$ (1), \\ Wagner Ferreira dos Santos ${ }^{1,2, *}$ \\ ${ }^{1}$ Neurobiology and Venoms Laboratory, Department of Biology, College of Philosophy, Sciences and Literature of Ribeirão Preto, University of São Paulo, \\ Ribeirão Preto, SP, Brazil. \\ ${ }^{2}$ Institute for Neurosciences and Behavior - INeC, Ribeirão Preto, SP, Brazil. \\ ${ }^{3}$ Department of Pharmacology and Physiology, Drexel University College of Medicine, Philadelphia, PA, USA.
}

\section{Article Info \\ Keywords: \\ L-Glutamate \\ excitotoxicity \\ neuroprotection \\ Parawixia bistriata \\ RT10}

\begin{abstract}
Background: $L$-Glutamate ( $L$-Glu), the major excitatory neurotransmitter in the mammalian Central Nervous System (CNS), is essential to cognitive functions. However, when $L$-Glu is accumulated in large concentrations at the synaptic cleft, it can induce excitotoxicity that results in secondary damage implicated in many neurological disorders. Current therapies for the treatment of neurological disorders are ineffective and have side effects associated with their use; therefore, there is a need to develop novel treatments. In this regard, previous studies have shown that neuroactive compounds obtained from the venom of the spider Parawixia bistriata have neuroprotective effects in vitro and in vivo. In this sense, this work aimed to evaluate potential neuroprotective effects of fraction RT10, obtained from this spider venom, on primary cultures of neuron and glial cells subjected to glutamate excitotoxicity insults.

Methods: Primary cultures of neurons and glia were obtained from the cerebral tissue of 1-day-old postnatal Wistar rats. After 7 days in vitro (DIV), the cultures were incubated with fraction RT10 $(0.002 ; 0.02 ; 0.2$ and $2 \mu \mathrm{g} / \mu \mathrm{L})$ or riluzole $(100 \mu \mathrm{M})$ for 3-hours before application of $5 \mathrm{mM} \mathrm{L}$-Glu. After 12 hours, the resazurin sodium salt (RSS) test was applied to measure metabolic activity and proliferation of living cells, whereas immunocytochemistry for MAP2 was performed to measure neuronal survival. In addition, the cells were immunolabeled with NeuN and GFAP in baseline conditions. Results: In the RSS tests, we observed that pre-incubation with RT10 before the excitotoxic insults from $L$-Glu resulted in neuroprotection, shown by a $10 \%$ reduction in the cell death level. RT10 was more effective than riluzole, which resulted in a cell-death reduction of 5\%. Moreover, qualitative analysis of neuronal morphology (by MAP2 staining, expressed as fluorescence intensity (FI), an indirect measure of neuronal
\end{abstract}

\footnotetext{
* Correspondence: wagnerf@usp.br

http://dx.doi.org/10.1590/1678-9199-JVATITD-1488-18

Received: 03 August 2018; Accepted: 15 January 2019; Published online: 16 May 2019
} 
survival) indicate that RT10 reduced the toxic effects of $L-G l u$, as shown by a $38 \%$ increase in MAP2 fluorescence when compared to $L$-Glu insult. On the other hand, the riluzole treatment resulted in $17 \%$ increase of MAP2 fluorescence; therefore, the neuroprotection from RT10 was more efficacious.

Conclusion: RT10 fraction exhibits neuroprotective effects against $L$-Glu excitotoxicity in neuron-glia cultured in vitro.

\section{Background}

$L$-Glutamate ( $L$-Glu) is the major excitatory neurotransmitter in the Central Nervous System (CNS) of mammals [1]. Glutamatergic neurotransmission is fundamental to cognitive functions, such as learning and memory. Nevertheless, overactivation of $L$-Glu receptors leads to a hyperexcitability, which induces an excessive calcium $\left(\mathrm{Ca}^{2+}\right)$ influx, which in turns results in excitotoxic-mediated cell death [2]. L-Glu transporters are responsible for glutamate clearance in the brain; therefore, they can be targeted for the development of therapies for CNS disorders, in which glutamate excitotoxicity plays an important role, such as Alzheimer's disease, amyotrophic lateral sclerosis (ALS), autism, stroke, Huntington's disease and epilepsy [2-5]. Another potential approach to development of therapies for these diseases would be an increase of GABAergic inhibitory neurotransmission, which may counteract the hyperexcitability of CNS mediated by $L$-Glu. In this context, compounds that either reduce $L$-Glu or enhance GABA concentrations at the synaptic cleft can provide therapeutic strategies against several neurological disorders. For instance, riluzole, a drug approved by the FDA (Food and Drug Administration) for ALS treatment, acts by inhibiting presynaptic release of $L$-Glu, preventing overexcitation of postsynaptic neurons and thus calcium influx, as well as intensifying GABAergic transmission, thereby exhibiting neuroprotective effects [6,7]. However, side effects associated with its use include anorexia, dizziness, diarrhea, headache and vomiting [8]. Thus, it is fundamental to seek new alternatives for treatments to provide a better life quality to the patients $[9,10]$. In this regard, venoms are natural sources for new compounds, since they present affinity and selectivity for a wide variety of targets in mammalian systems. Therefore, molecules derived from spider venoms that modulate CNS structures such as ion channels, receptors and transporters, should be studied and developed into therapies $[11,12]$. Furthermore, several pharmaceutical companies have developed venom-based drug discovery programs or used venom-derived molecules for target validation [13]. Our group has elucidated several biological and pharmacological activities of compounds isolated from the venom of the social spider Parawixia bistriata ( $P$. bistriata) $[14,15]$. Some of these compounds display anxiolytic, anticonvulsant and neuroprotective effects, by acting on $L$-Glu and GABA (gamma-Aminobutyric acid) transporters [11,16,17]. In the present work, we investigated a potential neuroprotective effect of RT10, a pool of molecules from P. bistriata venom, in primary cultures of neuron and glial cells exposed to excitotoxic insults by the application of a high concentration of $L$-Glu.

\section{Methods \\ Compound isolation}

Spiders were collected in the Brazilian state of São Paulo, near the city of Ribeirão Preto, according to Brazil's Chico Mendes Institute for the Biodiversity Conservation (ICMBio- SISBIO protocol $\left.n^{\circ} 46797\right)$. The specimens were euthanized by freezing at $-20^{\circ} \mathrm{C}$. Venom glands and reservoirs were carefully removed and crushed in Milli-Q water, centrifuged at $3000 \times \mathrm{g}$ for 10 min after which the supernatant was lyophilized and weighed. The resulting powder was submitted to fractionation by high performance liquid chromatography (HPLC; Shimadzu LC-6A; U.V. detector SPD-6AV; auto injector SIL-10ADvp, Shimadzu) using a previous methodology [18]. Briefly, lyophilized venom was dissolved in Milli-Q water $(12 \mathrm{mg} / \mathrm{mL})$ and applied onto a reverse-phase column (PREP-ODS $20 \times 250 \mathrm{~mm}, 5 \mu \mathrm{m}$ ) previously equilibrated with $99 \% \mathrm{H}_{2} \mathrm{O}$ (solvent $\mathrm{A}$ ) and $1 \%$ (v/v) Acetonitrile (ACN, solvent B). This sample was eluted by solvent $\mathrm{B}$ in a linear gradient from 1 to $100 \%$. The flow rate was $8.0 \mathrm{ml} / \mathrm{min}$ and elutes were continuously monitored at 215 and $245 \mathrm{~nm}$. Eighteen fractions were collected and lyophilized, which included the fraction studied herein, referred to as RT10 (Figure 1).

\section{Cell culture}

We obtained a co-culture composed of neurons and astrocytes, since both cell types exhibit the potential targets for RT10 action, such as GABA and $L$-Glu transporters [19]. Therefore, the addition of Cytosine- $\beta-D$-arabinofuranoside (AraC), an anti-mitotic agent that intercalates DNA in the mitotic phase and halts non-neuronal cell proliferation, was omitted, allowing for glial growth. However, the exact proportion of glial and neuronal population in these cultures remains to be investigated. Primary cultures of neuron and glial cells were obtained from cortex and hippocampus, which are affected by glutamatergic excitotoxicity in several neurodegenerative diseases [5]; furthermore, we optimized the number of primary cells to be cultured, in order to reduce the number of animals in each experiment. Thus, the brain tissue from 1-day-old newborn Wistar rats was removed, dissociated and plated onto 24-well culture plates (coated with poly-L-lysine, with coverslips for immunocytochemistry analysis and without coverslips for viability tests), at the density of $5 \times 10^{5}$ cells per 
well, in Neurobasal-A medium (Gibco, USA) containing 2\% B27 supplement (Gibco, USA), 1\% antibiotic (Penicillin-Streptomycin, Invitrogen, USA) and $0.5 \mathrm{mM}$ Glutamax supplement (Invitrogen, USA). Cultures were maintained at $37^{\circ} \mathrm{C}, 5 \% \mathrm{CO}_{2}$ in a humidified incubator until use with culture medium, which was changed every 2 to 3 days. Cells cultures were pretreated for 3 hours with either riluzole $(100 \mu \mathrm{M})$ or RT10 (at the following concentrations: $0.002 ; 0.02 ; 0.2$ and $2 \mu \mathrm{g} / \mu \mathrm{L})$ and then exposed to $L-\mathrm{Glu}(5 \mathrm{mM})$ for 12 hours in Locke's solution at 7 DIV [20]. Subsequently, cell viability tests or immunocytochemistry was performed as described below.

\section{Viability assays}

Cell viability in neuron-glia primary culture was assessed through the presence of $10 \%$ resazurin sodium salt (RSS, SigmaAldrich, USA), which is a non-toxic, permeable compound that is useful to measure metabolic activity and proliferation of living cells. RSS is a blue non-fluorescent dye that is reduced to the pink-colored, highly fluorescent resorufin, so that a higher fluorescence indicates a greater number of viable cells [21]. The fluorescence was measured in a spectrophotometer, with excitation at $530 \mathrm{~nm}$ and emission at $590 \mathrm{~nm}, 24$ hours after L-Glu insults [22].

\section{Immunocytochemistry}

Neurons and astrocytes were identified by immunocytochemistry labeling. We used the following primary antibodies: mouse anti-Neuronal Nuclei (NeuN; 1:500; Abcam, USA); rabbit antiMicrotubule associated protein 2 (MAP-2; 1:1000; Abcam, USA); chicken anti-Glial Fibrillary Acidic Protein (GFAP; 1:500; Abcam, USA) and secondary antibodies: goat anti-mouse IgG (Alexa Fluor 594; 1:1000, Abcam, USA); donkey anti-rabbit IgG (Alexa Fluor 488; 1:1000, Abcam, USA); rabbit anti-Chicken IgG (Alexa Fluor 405; 1:1000, Abcam, USA). The neurons and astrocytes immunolabeled with anti-NeuN and anti-GFAP were not exposed to $L$-Glu or treatments (RT10; riluzole). This part of immunostaining was performed to prove the presence of these cell types in the primary culture. However, we assessed the neuronal projections of cells affected by $L$-Glu exposure and treated by RT10 or riluzole, through anti-MAP2 immunolabeling. The images were analyzed by fluorescence microscopy (Leica Microsystems, Germany), with image acquisitions obtained via a camera system (Leica FX300; Leica Microsystems, Germany), coupled to the microscope with software for the acquisition and analysis of microscopic images, Leica Application Suite (LAS; Leica Microsystems, Germany).

\section{Data analysis}

The software "Image J" (https://imagej.nih.gov/ij/; USA) was employed to obtain the fluorescence intensity (FI) of neurons labeled with anti-MAP2.In this study, the higher the fluorescence, the more neuronal projections were present in the cultures.

\section{Statistical analysis}

The results from viability assays and FI for MAP2 immunocytochemistry were analyzed by ANOVA one way followed by Newman-Keuls test.

\section{Results}

\section{High performance liquid chromatography (HPLC)}

Fractionation of $P$. bistriata spider venom yielded, among other fractions, the RT10 fraction, which was characterized as a pool of compounds obtained in the first ten minutes of retention time and comprises Parawixin1 and Parawixin2 (Figure 1).

\section{Cellular viability}

Quantifications by RSS tests (Figure 2) indicate that cell-death levels were significantly reduced (by $10 \%$ ) by RT10 incubation at 2 $\mu \mathrm{g} / \mu \mathrm{L}$ after the insult but were not altered by lower concentrations. Treatment with riluzole resulted in a neuroprotective effect, shown by a $5 \%$ reduction in the cell-death level when compared to insult alone. Cultures treated with riluzole and RT10 in the absence of insult did not alter the cell viability.

\section{Immunocytochemistry}

Neurons and astrocytes present in the primary culture under control conditions are displayed in Figure 3, labeled with antiMAP2 (Figure 3A), anti-NeuN (Figure 3B) and anti-GFAP antibodies (Figure 3C). Representative images of cultures stained with MAP2 in different conditions are shown in Figure 4. Figure 4A (control conditions) shows the integrity of the neurons, whereas Figure $4 \mathrm{~B}$ and Figure $4 \mathrm{C}$ show that incubation with riluzole and RT10, at the indicated concentrations, did not result in toxicity. In Figure 4D, incubation with $L$-Glu $(5 \mathrm{mM})$ reduced the density of neurons (Figure 4D). On the other hand, incubation with riluzole (Figure 4E) and RT10 (Figure 4F) mitigated damage to cell projections, as shown by a higher density of anti-MAP2 labeling. Quantitative analysis (Figure 5) revealed that treatments with riluzole and RT10 were neuroprotective, as shown by respective increases of 17 and $38 \%$ in MAP2 fluorescence intensity (FI), in comparison with the insulted group. Treatments with riluzole and RT10 alone (Figure 4B, Figure 4C and Figure 5) did not result in significant differences between the FI and control cells.

\section{Discussion}

Parawixins1 and 2 are included in fraction RT10 (Figure 1) $[13,17,23]$. RT10 was neuroprotective in the cultures subjected to excitotoxicity by 12 hours of exposure to $L$-Glu. Data displayed in figures 2, 4 and 5 suggest that RT10 protects neurons, as demonstrated by enhancing the MAP2 fluorescence, indicating less cellular death. It is important to highlight that MAP2 is found mostly in dendrites [24]. Accordingly, the results indicated that $L$-Glu caused a decline of these neuronal 


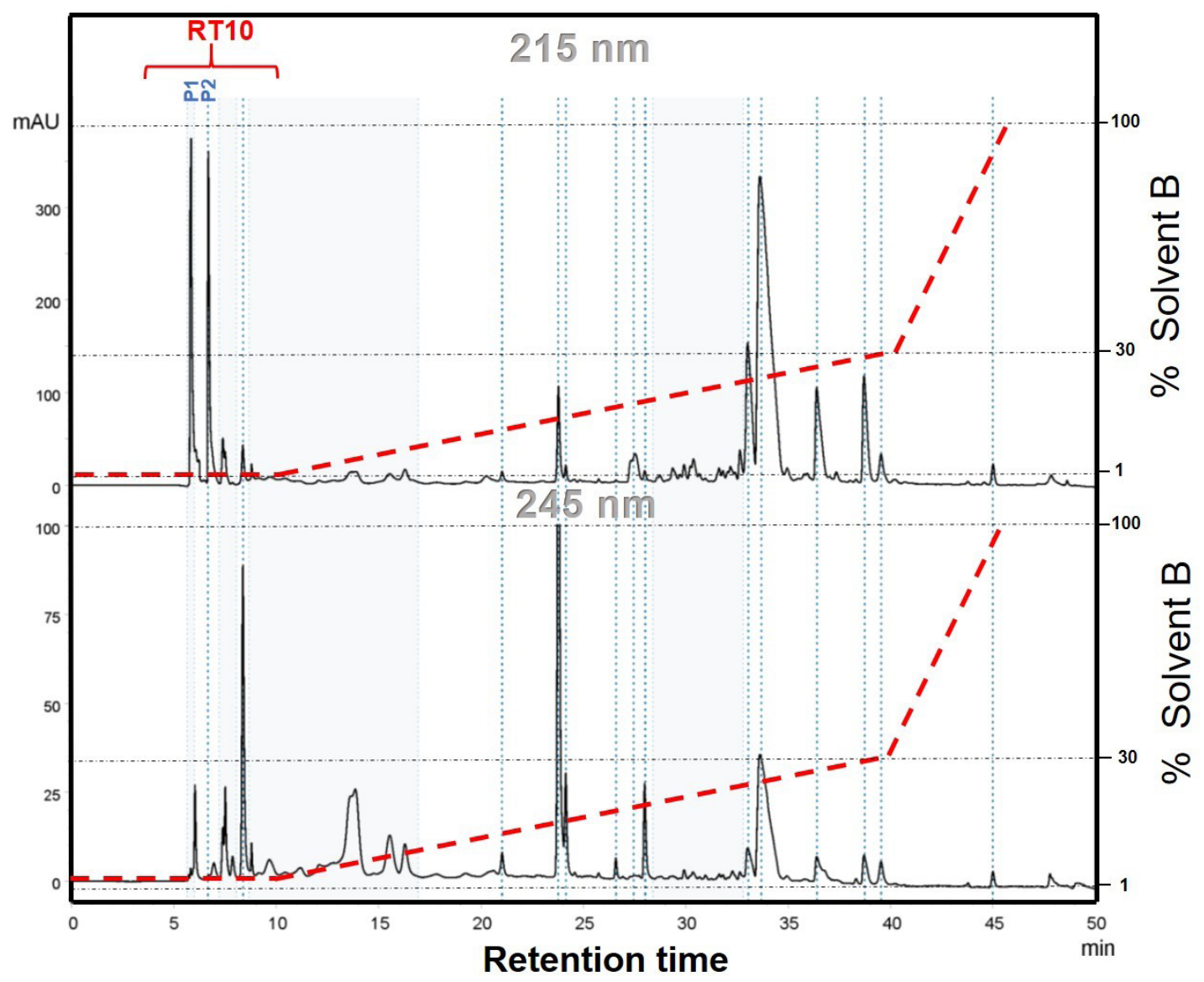

Figure 1. Representative chromatogram of the fractionation of $P$. bistriata spider venom in high-performance liquid chromatography (HPLC), with linear gradient of solvent $B$ (Acetonitrile) from 1 to $100 \%$. Flow rate in $8.0 \mathrm{ml} / \mathrm{min}$ and eluents monitored and recorded at $215 \mathrm{~nm}$ and $245 \mathrm{~nm}$. RT10= fraction studied in this work. P1=Parawixin1; P2=Parawixin2.

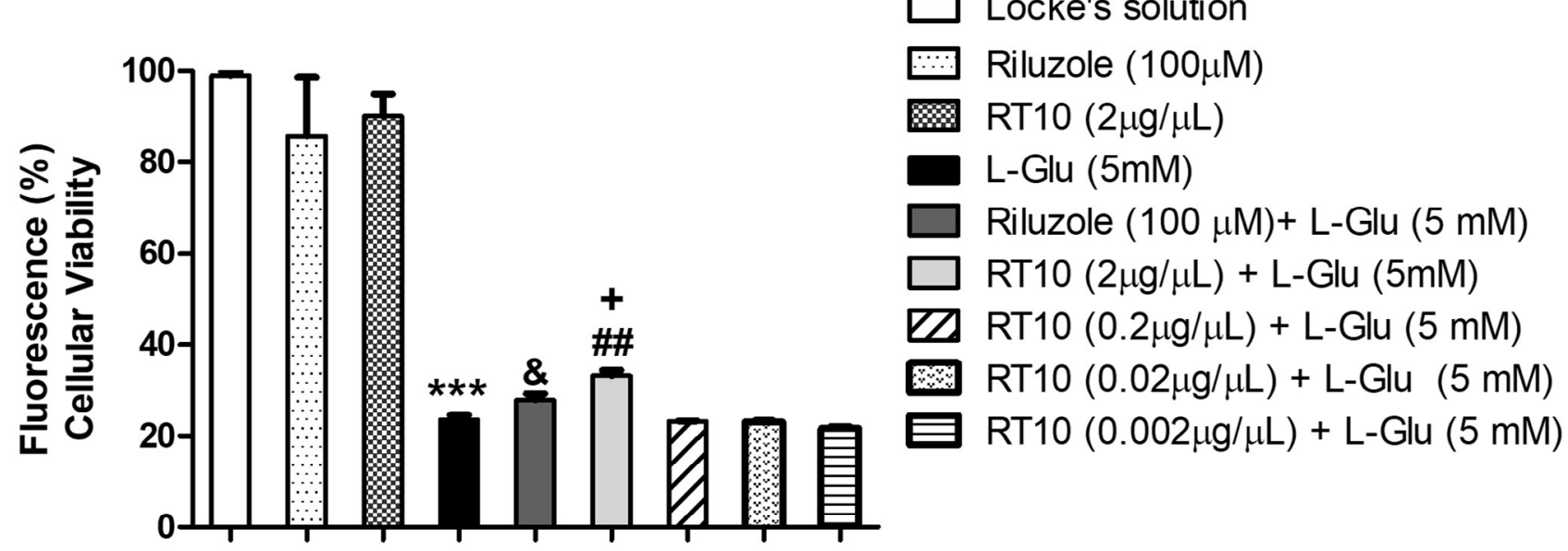

Figure 2. Cellular viability expressed in normalized levels of fluorescence (percent and standard deviation), after 12 hours incubation with $\mathrm{L}$-Glu ( $5 \mathrm{mM}$ ) to the cultures. Data is presented as mean \pm S.E.M. Treatments with riluzole $(100 \mu \mathrm{M})$ and RT10 $(0.002 ; 0.02 ; 0.2$ and $2 \mu g / \mu \mathrm{L})$ for $3 \mathrm{~h}$, before insults, produced insignificant differences. (*** $p<0.001$ vs. Locke's solution group; \&p<0.05 and \#\#p<0.01 vs. L-Glu-5 mM; $+p<0.05$ vs riluzole+L-Glu 5 mM). One-way ANOVA followed by Newman-Keuls test. 


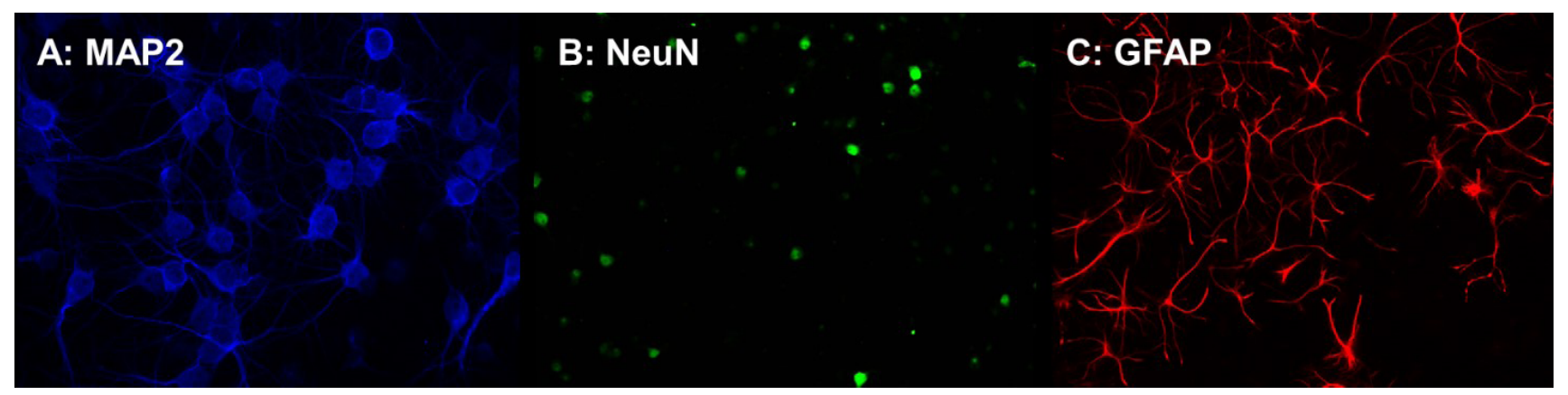

Figure 3. Immunofluorescence photomicrographs of primary cortical and hippocampus neuron/glia cultures in vitro (7 DIV) from Wistar rat brains. Anti-MAP2 (a) anti-NeuN (b) and anti-GFAP (c) in control conditions. 200x magnification.

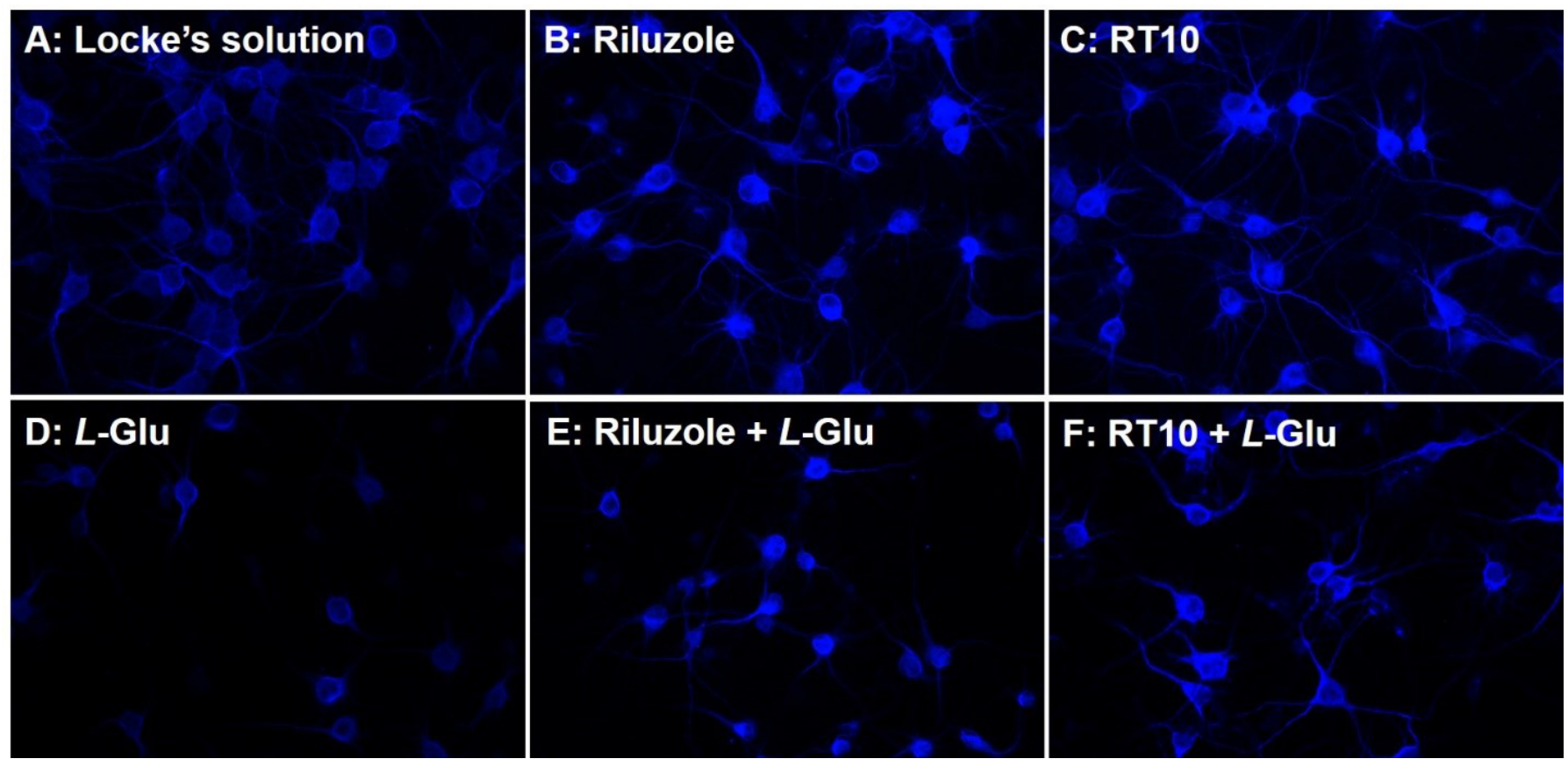

Figure 4. Immunological labeling with anti-MAP2 in primary cortical neuron/glia cultures. Treatments were performed three hours prior to incubation of $L-G l u$,

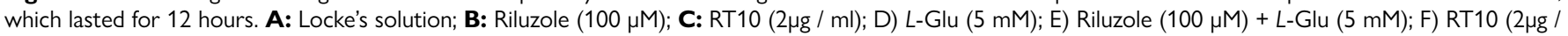
$\mathrm{ml})+\mathrm{L}-\mathrm{Glu}(5 \mathrm{mM}) .200 x$ magnification.

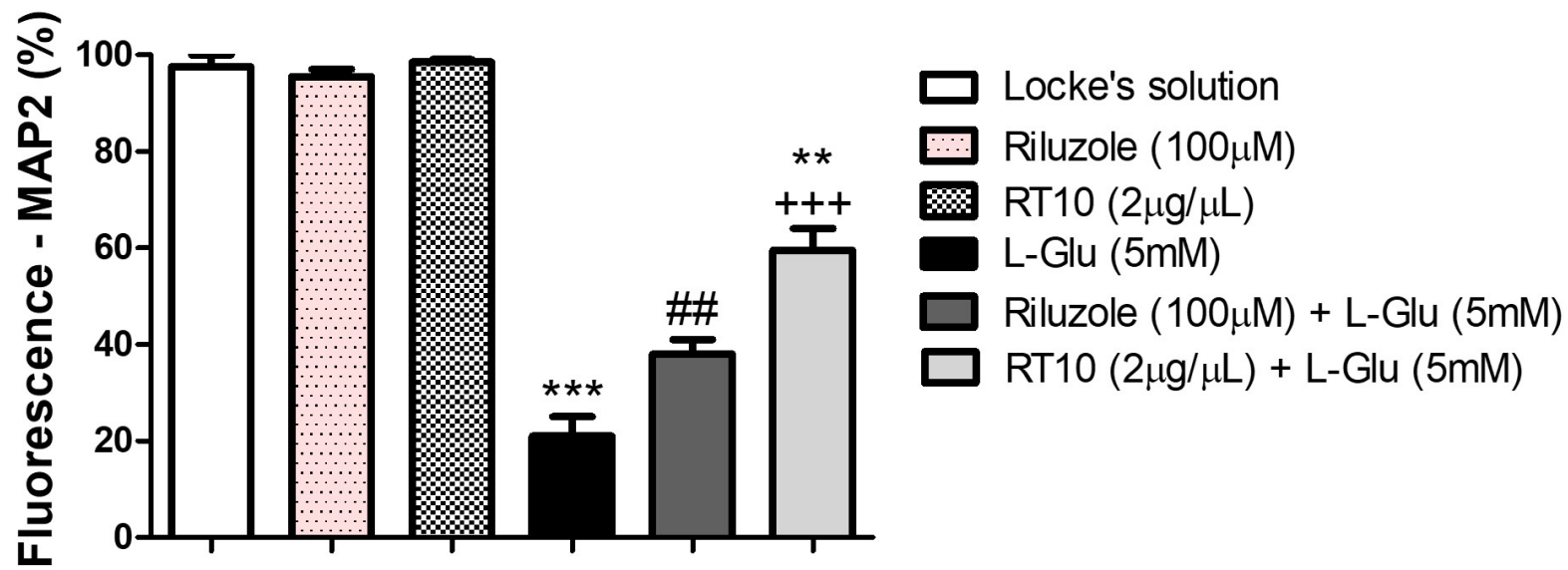

Figure 5. Normalized levels of FI in cells labeled with MAP2. Data are expressed as mean \pm S.E.M. Cultures were treated with either riluzole (100 $\mu$ M) or RT10 $(2 \mu \mathrm{g} / \mu \mathrm{L})$ for 3 hours prior to exposure to L-Glu $(5 \mathrm{mM})$ for 12 hours. (*** $<0.001$ vs Locke's solution group; \#\#p<0.01 vs. L-Glu; $+++p<0.001 \mathrm{vs.} \mathrm{L-Glu} \mathrm{and}$ ** $p<0.01$ vs. riluzole). One-way ANOVA followed by Newman-Keuls test. 
projections, which were preserved by RT10. We hypothesized that the observed neuroprotection resulted from previously reported activities of Parawixin1 and Parawixin2 in glutamate and GABA transporters, respectively [18,23]. Furthermore, Parawixin1 was shown to increase the function of Excitatory Amino Acid Transporter 2 (EAAT2), the main subtype of $L$-Glu transporter, which could explain the neuroprotective effects observed in the current work, due to the enhancement of transporter action that results in a lower amount of $L$-Glu in extracellular space, and consequent reductions of $\mathrm{Ca}^{2+}$ influx and cell death [4-17]. Parawixin2 was shown to reduce GABA and Glycine uptake, but did not modulate the activity of $\mathrm{Na}^{+}, \mathrm{K}^{+}$or $\mathrm{Ca}^{2+}$ ions or of GABA receptors in synaptosomes from the cerebral cortex of rats [18]. Moreover, Parawixin2 demonstrated neuroprotection and anticonvulsant activities in animal models of temporal lobe epilepsy and acute glaucoma $[13,18,25]$. Since it is responsible for increasing of GABA in extracellular space, Parawixin2 potentiates the inhibitory neurotransmission in order to counterbalance the harmful overactivated glutamatergic neurotransmission $[13,18,26]$. We emphasized that several concentrations of RT10 were assessed in the assays of cellular viability in which the highest concentration $(2 \mu \mathrm{g} / \mu \mathrm{L})$ was most effective, consequently, this was evaluated in the immunocytochemistry assay for MAP2. In the present study, riluzole was used as the control treatment, given its neuroprotective effects and suitability for patients with ALS or other neuropathologies. This drug has been shown to act in several mechanisms against glutamatergic neurotransmission, such as enhancing the activity of $L$-Glu transporters in astrocytes, by inhibiting $\mathrm{Ca}^{2+}$ influx in ion channels at the $L$-Glu receptors $[10,27]$. Furthermore, Mantz et al. [28] reported that riluzole presents inhibitory effects on GABA transporters. In the present study, RT10 revealed a greater neuroprotective effect than riluzole, as shown in quantitative and qualitative assays (Figure 2 and Figure 4). The mixed primary culture utilized in the current study was essential for investigating the neuroprotective effect of RT10, since Parawixin1 targets glutamatergic transporters and Parawixin2 targets GABA transporters. It is important to highlight the presence of transporters for glutamate and GABA in neurons and astrocytes, thereby highlighting the functional importance of the latter in the regulation of neurotransmitter levels in the synaptic cleft and hence for the activity of excitatory and inhibitory neurotransmission [29]. Immunocytochemistry and cellular viability assays were performed in 7 DIV cultures, a period in which mature neurons express the machinery that is susceptible to toxicity by $L$-Glu, for example the expression of the NR2A subunit of the NMDA (N-methyl-D-aspartate) receptor, which is essential for excitotoxicity and $\mathrm{Ca}^{2+}$ influx in a voltage-dependent channel [30]. In addition, Janssens and Lesage (2001) found that the NMDA receptor subunits (NR1, NR2A, and NR2B) were expressed in primary neuron cultures from rat cortex and hippocampus on the 7th DIV. We have not examined whether RT10 modulates the activity of NMDA receptors; such studies should be conducted in the future. The RT10 fraction, comprised of compounds Parawixin1 and Parawixin2, was studied under the premise supported by several studies $[12,31,32]$ that drug action can involve plural targets to address disease in more subtle and effective ways. In the current work, we have demonstrated a neuroprotective effect of the RT10 fraction against excitotoxicity in vitro. Nevertheless, it remains to be evaluated whether a neuroprotective effect would be observed if RT10 were added after the insults. This study is an important step towards developing alternative treatments for neurological disorders, which are associated with glutamatergic excitotoxicity. Future investigations should elucidate other possible mechanisms of RT10 and ascertain possible neuroprotective properties in in vivo models.

\section{Conclusion}

The RT10 fraction from P. bistriata spider venom is neuroprotective in neuroglia cultures exposed to toxic concentrations of $L$-Glu. In addition, the RT10 fraction exhibits a better effect than riluzole. These findings corroborate previous studies, in which Parawixin 1 and Parawixin2, two constituents of RT10, were found to be neuroprotective and anticonvulsant in in vivo experimental models. Therefore, we consider RT10 to be a valuable tool for designing new drugs against neurodegenerative diseases.

\section{Acknowledgements}

The authors are grateful to the biologist Mrs. Thalita Riul Prado for animal care and Prof. Dr. Norberto Peporine Lopes (Department of Physics and Chemistry, College of Pharmaceutical Sciences of Ribeirão Preto) to allow the use of HPLC equipment.

\section{Abbreviations}

ALS: Amyotrophic lateral sclerosis; FDA: Food and Drug Administration; FI: Fluorescence intensity; GABA: GammaAminobutyric acid; GFAP: Glial Fibrillary Acidic Protein; HPLC: High performance liquid chromatography; $L$-Glu- $L$ : Glutamate; MAP2: Microtubule associated protein 2; NeuN: Neuronal Nuclei; NMDA: N-methyl-D-aspartate; P. bistriata: Parawixia bistriata; P1: Parawixin1; P2: Parawixin2; RSS: Resazurin sodium salt.

\section{Availability of data and materials}

The data generated and analyzed during the current study are available from the corresponding author upon reasonable request.

\section{Funding}

This study was supported by the São Paulo Research Foundation FAPESP (2005/60254-0). Coordination for the Improvement of Higher Education Personnel (CAPES, scholarship to JLL). National Council for Scientific and Technological Development (CNPq), PNPD program, Post-doctoral scholarship to EOP. Moreover, this publication was supported in part by the Coordination for the Improvement of Higher Education Personnel (CAPES) through "Programa Editoração CAPES" - call No. 3/2016, grant No. 
0722/2017, record No. 88881.142062/2017-01 and by the National Council for Scientific and Technological Development (CNPq) and Coordination for the Improvement of Higher Education Personnel (CAPES) through "Programa Editorial CNPq/CAPES" call No. 18/2018, grant No. 404770/2018-5.

\section{Competing interests}

The authors declare that they have no competing interests.

\section{Authors' contributions}

EOP was responsible for carrying out the experiments, extraction and analysis of spider venom and writing of the manuscript. JLL was responsible for experiment design, data analysis and writing and correction of the manuscript. ACKF was responsible for manuscript correction, including English assistance and discussion of the results. WFS was the major contributor to the project, coordinated the whole team, assisted in the project design, contributed to writing the manuscript and analyzing the data, searched for funding, assisted in the project design and advised EOP. All authors read, corrected and approved the final manuscript.

\section{Ethics approval and consent to participate}

Not applicable.

\section{Consent for publication}

Not applicable.

\section{References}

1. Zhou Y, Danbolt NC. Glutamate as a neurotransmitter in the healthy brain. J Neural Transm. 2014;121(8):799-817.

2. Danbolt NC. Glutamate uptake. Prog Neurobiol. 2001;65(1):1-33.

3. Takahashi K, Foster JB, Lin CL. Glutamate transporter EAAT2: regulation, function, and potential as a therapeutic target for neurological and psychiatric disease. Cell Mol Life Sci. 2015;72(18):3489-506.

4. Fontana AC. Current approaches to enhance glutamate transporter function and expression. J Neurochem. 2015;134(6):982-1007.

5. O'Donovan SM, Sullivan CR, McCullumsmith RE. The role of glutamate transporters in the pathophysiology of neuropsychiatric disorders. NPJ Schizophr. 2017;3(1):32.

6. Shaw PJ, Ince PG. Glutamate, excitotoxicity and amyotrophic lateral sclerosis. J Neurol. 1997;244(Suppl 2):S3-14.

7. Miller RG, Mitchell JD, Lyon M, Moore DH. Riluzole for amyotrophic lateral sclerosis (ALS)/ motor neuron disease (MND). Cochrane Database Syst Rev. 2002;(2):CD001447.

8. Vucic S, Lin CS, Cheah BC, Murray J, Menon P, Krishnan AV, et al. Riluzole exerts central and peripheral modulating effects in amyotrophic lateral sclerosis. Brain. 2013;136(Pt 5):1361-70.

9. Zarate CA, Manji HK. Riluzole in psychiatry: a systematic review of the literature. Expert Opin Drug Metab Toxicol. 2008;4(9):1223-34.

10. Lamanauskas $\mathrm{N}$, Nistri A. Riluzole blocks persistent $\mathrm{Na}+$ and $\mathrm{Ca} 2+$ currents and modulates release of glutamate via presynaptic NMDA receptors on neonatal rat hypoglossal motoneurons in vitro. Eur J Neurosci. 2008;27(10):2501-14.

11. de O Beleboni R, Pizzo AB, Fontana AC, de O G Carolino R, CoutinhoNetto J, dos Santos WF. Spider and wasp neurotoxins: pharmacological and biochemical aspects. Eur J Pharmacol. 2004;493(1-3):1-17.

12. Ambure P, Bhat J, Puzyn T, Roy K. Identifying natural compounds as multi-target- directed ligands against Alzheimer's disease: an in silico approach. J Biomol Struct Dyn. 2018:1-25.
13. Godoy LD, Liberato JL, Celani MVB, Gobbo-Neto L, Lopes NP, dos Santos WF. Disease modifying effects of the spider toxin Parawixin2 in the experimental epilepsy model. Toxins (Basel). 2017;9(9):262.

14. Fachim HA, Cunha AO, Pereira AC, Beleboni RO, Gobbo-Neto L, Lopes NP, Coutinho-Netto J, dos Santos WF. Neurobiological activity of Parawixin 10, a novel anticonvulsant compound isolated from Parawixia bistriata spider venom (Araneidae: Araneae). Epilepsy Behav. 2011;22(2):158-64.

15. Liberato JL, Cunha AO, Mortari MR, Gelfuso EA, Beleboni Rde O, Coutinho-Netto J, dos Santos WF. Anticonvulsant and anxiolytic activity of FrPbAll, a novel GABA uptake inhibitor isolated from the venom of the social spider Parawixia bistriata (Araneidae: Araneae). Brain Res. 2006;1124(1):19-27.

16. Gelfuso EA, Cunha AO, Mortari MR, Liberato JL, Paraventi KH, Beleboni $\mathrm{RO}$, et al. Neuropharmacological profile of FrPbAll, purified from the venom of the social spider Parawixia bistriata (Araneae, Araneidae), in Wistar rats. 2007;80(6):566-72.

17. Fontana AC, Beleboni RO, Wojewodzic MW, Ferreira dos Santos W, Coutinho-Netto J, Grutle NJ, et al. Enhancing glutamate transport: mechanism of action of Parawixin1, a neuroprotective compound from Parawixia bistriata spider venom. Mol Pharmacol. 2007;72(5):1228-37.

18. Beleboni RO, Guizzo R, Fontana AC, Pizzo AB, Carolino RO, Gobbo-Neto $L$, et al. Neurochemical characterization of a neuroprotective compound from Parawixia bistriata spider venom that inhibits synaptosomal uptake of GABA and glycine. 2006;69(6):1998-2006.

19. Zhou Y, Danbolt NC. GABA and glutamate transporters in brain. Front Endocrinol (Lausanne). 2013;4:165.

20. Tayeboon GS, Tavakoli F, Hassani S, Khanavi M, Sabzevari O, Ostad SN. Effects of Cymbopogon citratus and Ferula assa-foetida extracts on glutamateinduced neurotoxicity. In Vitro Cell Dev Biol Anim. 2013;49(9):706-15.

21. Rampersad SN. Multiple applications of Alamar Blue as an indicator of metabolic function and cellular health in cell viability bioassays. Sensors (Basel). 2012;12(9):12347-60.

22. White MJ, DiCaprio MJ, Greenberg DA. Assessment of neuronal viability with Alamar Blue in cortical and granule cell cultures. J Neurosci Methods. 1996;70(2):195-200.

23. Fontana AC, Guizzo R, de Oliveira Beleboni R, Meirelles e Silva AR, Coimbra NC, Amara SG, et al. Purification of a neuroprotective component of Parawixia bistriata spider venom that enhances glutamate uptake. Br J Pharmacol. 2003;139(7):1297-309.

24. Conde $C$, Cáceres A. Microtubule assembly, organization and dynamics in axons and dendrites. Nat Rev Neurosci. 2009;10(5):319-32.

25. Liberato JL, Godoy LD, Cunha AOS, Mortari MR, Beleboni RDO, Fontana ACK, et al. Parawixin2 Protects Hippocampal Cells in Experimental Temporal Lobe Epilepsy. Toxins (Basel). 2018; 10:2-27.

26. Petroff OA. GABA and glutamate in the human brain. Neuroscientist. 2002;8(6):562-73.

27. Nagoshi N, Nakashima H, Fehlings MG. Riluzole as a neuroprotective drug for spinal cord injury: from bench to bedside. Molecules. 2015;20(5):7775-89.

28. Mantz J, Laudenbach V, Lecharny JB, Henzel D, Desmonts JV. Riluzole, a novel antiglutamate, blocks GABA uptake by striatal synaptosomes. Eur J Pharmacol. 1994;257(1-2):7-8.

29. Schousboe A. Role of astrocytes in the maintenance and modulation of glutamatergic and GABAergic neurotransmission. 2003;28(2):347-52.

30. Brewer LD, Thibault O, Staton J, Thibault V, Rogers JT, Garcia-Ramos G, et al. Increased vulnerability of hippocampal neurons with age in culture: temporal association with increases in NMDA receptor current, NR2A subunit expression and recruitment of L-type calcium channels. Brain Res. 2007;1151(1):20-31.

31. Janssens N, Lesage AS. Glutamate receptor subunit expression in primary enteric glia cultures. J Recept Signal Transduct Res. 2001;33(4):1457-74.

32. Nikolic K, Mavridis L, Djikic T, Vucicevic J, Agbaba D, Yelekci K, et al. Drug design for CNS diseases: Polypharmacological profiling of compounds using cheminformatic, 3D-QSAR and virtual screening methodologies. Front Neurosci. 2016;10(265):1-21. 